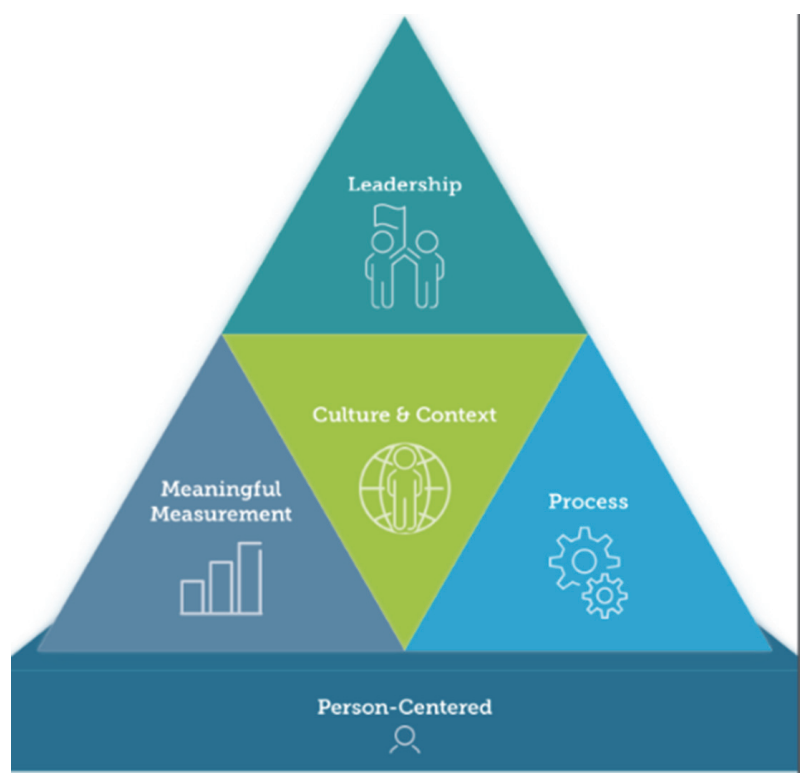

Abstract 22 Figure 1

implementation that stewards meaningful change. It is based on extensive literature reviews and an exhaustive series of six focus groups and 20 individual interviews with CRICO members. Ariadne Labs then conducted face validity testing, a review to test the extent to which the framework appears effective in terms of its stated aims.

Results The framework's domains are:

- Leadership: Essential functions for leaders to support implementation, including governance, prioritization, and accountability.

- Culture and Context: setting the norms and expectations that create an atmosphere in which everyone feels responsible for safety and pursues it daily.

- Process: the interrelated actions that are vital to transform ideas into a tangible solution on the ground.

- Meaningful Measurement: creating measures that are actionable, feasible, streamlined, and focused on improving the most crucial aspects of patient care.

- Person-Centeredness: creating mutually beneficial partnerships between patients, their families and those delivering health care services.

Conclusions The patient safety adoption framework will be used to help guide patient safety implementations across institutions, ensuring all key elements are addressed by:

- providing leadership, implementation teams, and others with a shared language and understanding of implementation for communicating and planning together; and

- assessing readiness for implementation and targeting areas needing improvement with the accompanying implementation readiness questions.

\section{COACHING INSIGHTS FROM SUPPORTING MULTIDISCIPLINARY TEAMS DURING A QI COLLABORATIVE}

Kerri Ann Deloso, Mary R Webster. Population Health Improvement Partners
Background To provide the best care for children with medical complexities (CMC) a multidisciplinary approach is required. As a part of a 4-year collaborative created to improve well-being for CMC, 10 states convened multidisciplinary teams (MDTs) with representatives from Title V, family and youth-led organizations, clinical sites, insurers, and state departments. Each team implemented a QI project focused on at least one of the collaborative's prioritized topic areas (see figure 1).

Objectives Share observed lessons learned, themes, and techniques for facilitating the creation and maintenance of highfunctioning MDTs from a QI coach perspective.

Methods As a part of the collaborative, each team was assigned a QI coach from Population Health Improvement Partners. Coaches worked alongside teams to help guide and encourage the design, implementation, sustainability, and spread of QI projects (see table 1).

Through regular interactions and review of collaborative deliverables, coaches observed the structures, interactions, and effectiveness of each MDT.

Results Having a QI coach was a value-added resource for state teams while they were forming and maintaining their MDTs (see figure 2). In addition, coaches were able to glean insights from coaching the teams, including lessons learned and techniques around:

- Engaging family and youth partners;

- Creating meaningful partnerships with system-level stakeholders, like Title V and Medicaid;

- Ensuring equitable distribution of power within teams;

- Utilizing QI and project management tools to help facilitate team interactions;

- Using data and visuals to bring the teams' stories to life and encourage buy-in; and

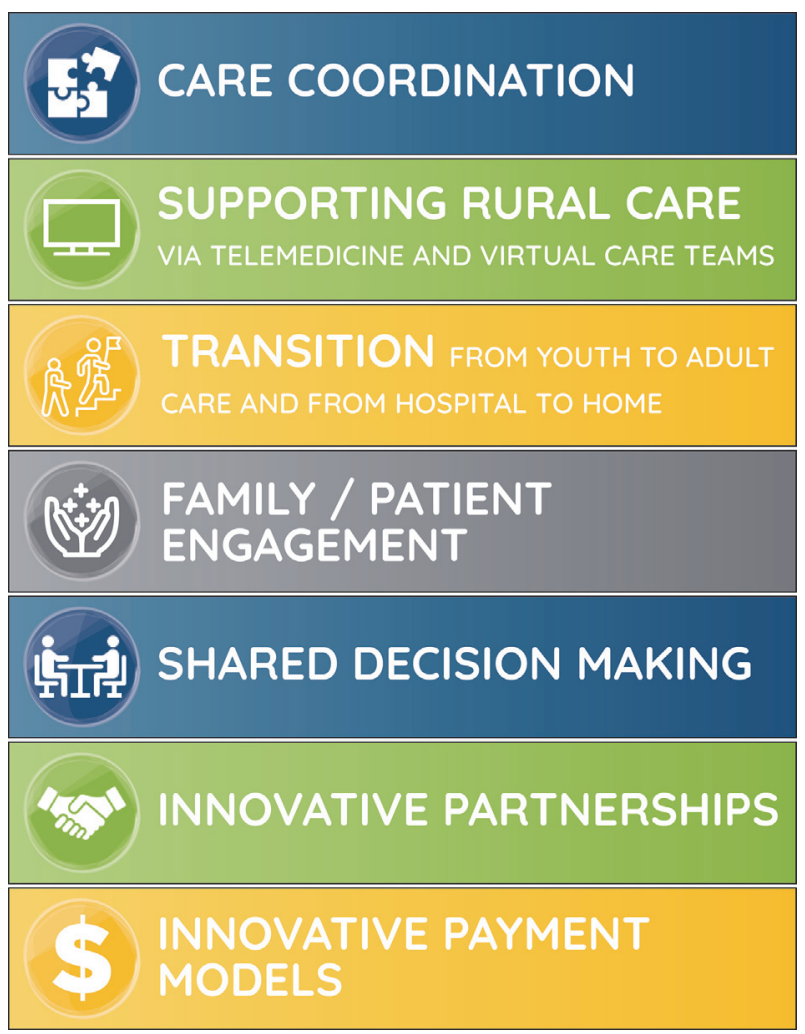

Abstract 23 Figure 1 Collaborative's menu of topic areas 
- Adapting during challenges, like COVID19 (figure 3).

Conclusions The creation of high-functioning MDTs is critical for addressing the complex, system-wide health care problems \& barriers experienced by CMC and their families. Coaching can act as a critical tool to not only facilitate the creation and maintenance of effective MDTs, but also document and share lessons learned. We hope our observations from this collaborative will both add to the knowledge base for coaching improvement teams and inform the creation of MDTs in future improvement work.

Having a coach who was "a part of the team" helped encourage innovation, as they were able to ask questions from an
outside perspective. overcome barriers and work through decisions.

Cै5 Coaches helped connect how QI activities directly translate into impact on a family's life.

Coaches were encouraging and helped provide validation to teams.

Coaches were great at listening, synthesizing, and making both big picture and situation specific recommendations.

(4) Coaches were able to bring teams working on similar tests of change together for collaborative learning.

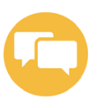

Coaching calls facilitated effective team functioning by providing a safe space to brainstorm and voice concerns.

The coaching perspective was critical in keeping the conversation around measures improvement-oriented.

1 Coaches provided tools to assist in building team consensus. Gemba walks, for example, helped center and focus teams by highlighting what's important to families.

Abstract 23 Figure 2 Themes from state teams re: the value of QI coaching

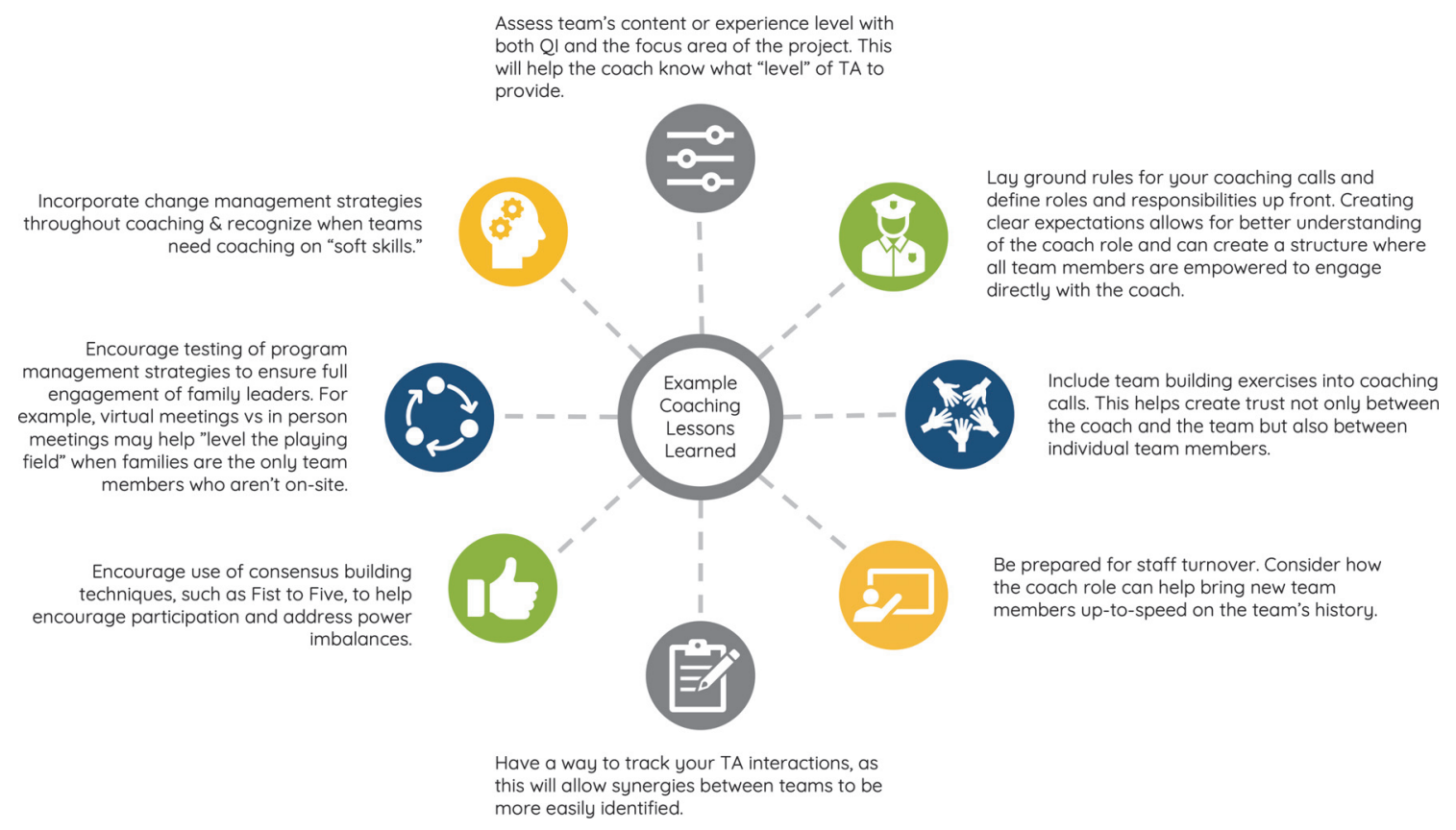

Abstract 23 Figure 3 Example coaching lessons learned 
Abstract 23 Table 1 Sample coaching roles/interventions

\begin{tabular}{|c|c|c|c|c|}
\hline & Year 1 & Year 2 & Year 3 & Year 4 \\
\hline & \multicolumn{4}{|c|}{$\begin{array}{l}\text { Continuing activities: monthly coaching calls, monthly webinars, annual learning sessions, on-site consultation visits, ad- } \\
\text { hoc affinity group calls, and ad-hoc individualized technical assistance }\end{array}$} \\
\hline 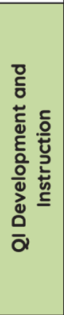 & $\begin{array}{l}\text { Collaborative-wide } \\
\text { introduction to QI methods } \\
\text { and tools } \\
\text {-Model for Improvement } \\
\text {-AIM and charter } \\
\text {-PDSA } \\
\text {-Introduction to measures } \\
\text {-Data collection \& display } \\
\text { (run charts) } \\
\text {-System mapping } \\
\text {-Root cause analysis } \\
\text { (pareto, fishbone, force field } \\
\text { analysis) }\end{array}$ & $\begin{array}{l}\text {-PDSA \& tracking } \cdot \text { Measure } \\
\text { refinement } \\
\text {-Data collection tool } \\
\text { development } \\
\text {-Using data for } \\
\text { improvement } \\
\text {-Observational walks } \\
\text { - Process mapping } \\
\text { - Change management \& } \\
\text { addressing resistance } \\
\text { - Incorporating sustainability } \\
\text { into project planning }\end{array}$ & $\begin{array}{l}\text { - Data workbook } \\
\text { development for improved } \\
\text { measure display } \\
\text { - Run chart use \& instruction } \\
\text { - Spread strategies } \\
\text { - Equity principles and QI } \\
\text { - Responsive TA to meet } \\
\text { additional state team } \\
\text { requests }\end{array}$ & $\begin{array}{l}\text {-Sustainability \& } \\
\text { dissemination focus } \\
\text {-Using Ql principles for final } \\
\text { year planning } \\
\text {-Using your data to tell your } \\
\text { story } \\
\text { - Responsive TA to meet } \\
\text { additional state team } \\
\text { requests }\end{array}$ \\
\hline 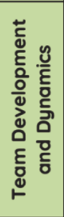 & $\begin{array}{l}\text {-Stage awareness \& } \\
\text { activities } \\
\text {-Change Management } \\
\text {-Roles \& responsibilities } \\
\text {-Project lead guidance } \\
\text {-Team meeting structure }\end{array}$ & $\begin{array}{l}\text { - Onboarding family leaders } \\
\text { onto clinical teams } \\
\text {-Data collection tips \& tools } \\
\text {-Individualized coaching } \\
\text { activities for yearly consult } \\
\text { visits per team }\end{array}$ & $\begin{array}{l}\text {-Adapting to COVID19 } \\
\text {-Continued stakeholder } \\
\text { engagement } \\
\text { - Communication plans } \\
\text {-Family team member } \\
\text { engagement activities } \\
\text { (FESAT and action plan } \\
\text { guidance) }\end{array}$ & $\begin{array}{l}\text {-Planning for adjourning } \\
\text {-Celebrating learnings and } \\
\text { successes } \\
\text { - Developing final project } \\
\text { deliverables, including } \\
\text { learning session } \\
\text { presentations, product } \\
\text { pitches, impact statements, } \\
\text { and final team chapters }\end{array}$ \\
\hline 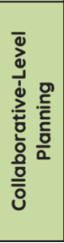 & $\begin{array}{l}\text {-Planning \& co-faculty for } \\
\text { learning sessions and } \\
\text { monthly webinars (all } \\
\text { years) } \\
\text {-Building collaborative } \\
\text { relationships with project } \\
\text { partners }\end{array}$ & $\begin{array}{l}\text {-Bi-monthly contacts with } \\
\text { collaborative leads: report } \\
\text { out on team progress and } \\
\text { needs } \\
\text {-Data discussions on team } \\
\text { and aggregate level }\end{array}$ & $\begin{array}{l}\text {-Sustainability \& spread } \\
\text { planning } \\
\text {-Bi-monthly contact with } \\
\text { project collaborative } \\
\text { partners } \\
\text {-Co-planning individual } \\
\text { state team consultation } \\
\text { visits (years 3-4) } \\
\text {-Co-led affinity groups by } \\
\text { project role (years 3-4) }\end{array}$ & $\begin{array}{l}\text {-Sustainability and spread } \\
\text { activities } \\
\text { - Data use and evaluation } \\
\text { - Product dissemination } \\
\text { plans } \\
\text { - Capturing areas for } \\
\text { publication } \\
\text { - Final chapter guidance for } \\
\text { teams }\end{array}$ \\
\hline
\end{tabular}

\section{4}

\section{0,000 REASONS QI WORKS: A VACCINE STORY}

Rachel Beitlich, Amber Larson, Emily Mishek. Park Nicollet/HealtPartners

\subsection{6/bmjoq-2021-IHI.24}

Background In late 2020, in the midst of a surge of COVID19 in Minnesota, the Pfizer/BioNTech vaccine was granted emergency use authorization. HealthPartners CEO Andrea Walsh challenged our organization to provide a plan for administering 10,000 COVID-19 vaccines a day, and Park Nicollet Methodist Hospital leveraged our history of quality improvement to rapidly plan, execute, and scale vaccine administration.

Objectives

- Timely vaccination of multiple populations (healthcare workers, high-risk patient populations, and general public)

- Operate efficiently under several constraints (space, staffing, and vaccine supply)

Methodist POD Covid-19 Vaccination | VSM Current State January 2021

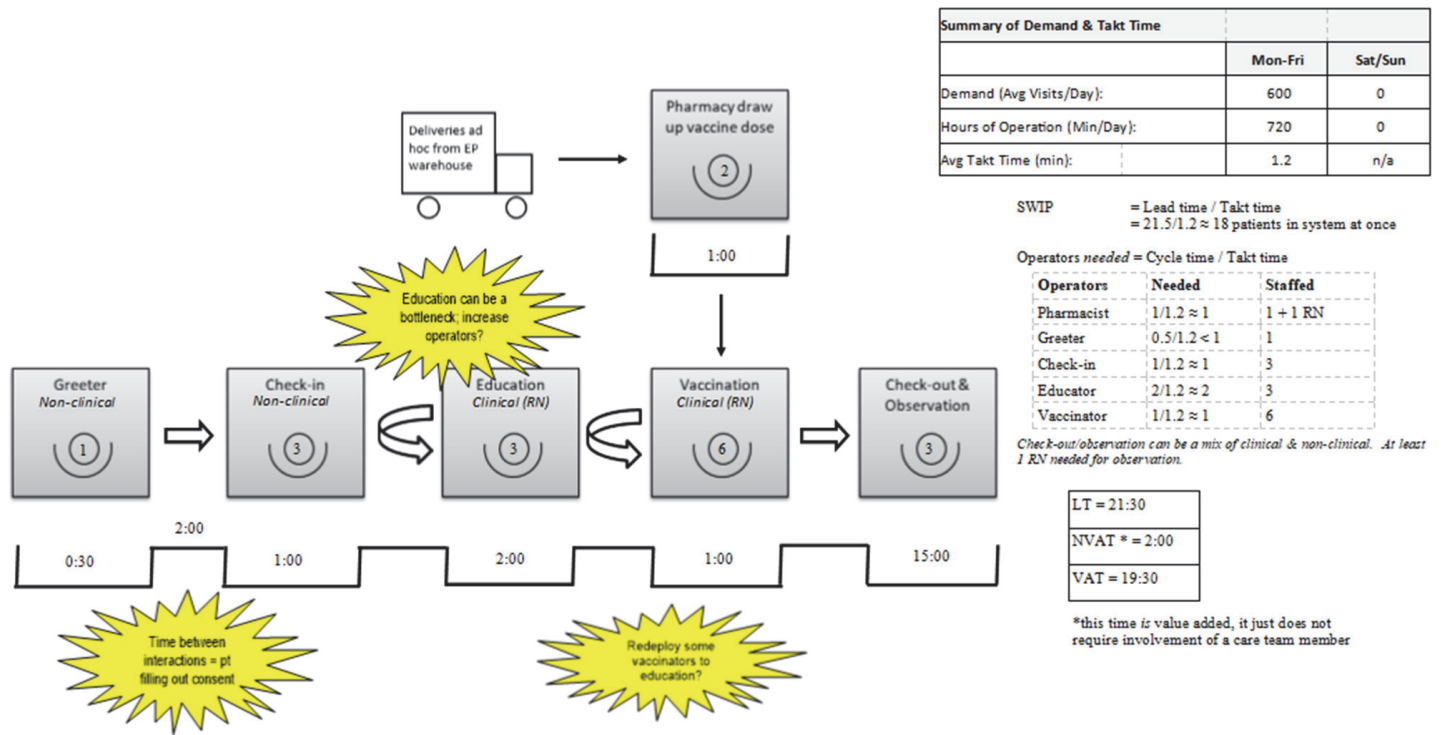

Abstract 24 Figure 1 Initial value stream map of clinic operations. Scaled to predict staffing needs in order to achieve 10,000 vaccines a day using the same model 